\title{
Effect of Wearing Medical Masks on Perioperative Respiratory Complications in Older Adults with Hip Fracture: A Retrospective Cohort Study
}

\author{
Mingming $\mathrm{Fu}^{\mathrm{l}, *}$ \\ Junfei Guo ${ }^{2, *}$ \\ Yaqian Zhang' \\ Yuqi Zhao' \\ Yingze Zhang ${ }^{2-4}$ \\ Zhiqian Wang' \\ Zhiyong $\mathrm{Hou}^{2,3}$
}

'Department of Geriatric Orthopedics, The Third Hospital of Hebei Medical University, Shijiazhuang, Hebei, People's Republic of China; ${ }^{2}$ Department of Orthopaedic Surgery, the Third Hospital of Hebei Medical University, Shijiazhuang, Hebei, 05005I, People's Republic of China; ${ }^{3} \mathrm{NHC}$ Key Laboratory of Intelligent Orthopaedic Equipment (The Third Hospital of Hebei Medical University), Shijiazhuang, China; ${ }^{4}$ Chinese Academy of Engineering, Beijing, 100088, People's Republic of China

*These authors contributed equally to this work

\begin{abstract}
Purpose: Respiratory complication is one of the major challenges in the treatment of older adults with hip fractures. However, no study so far has investigated the effect of wearing medical masks on the prevention of perioperative respiratory complications in these patients. Patients and Methods: In this retrospective cohort study, 1016 consecutive patients aged $\geq 65$ years with hip fractures were included and assigned to two groups: the control group and the observation group. The two groups received the same perioperative management modalities. In addition, patients in the observation group were asked to wear medical masks for protection. Data of patients' demographics, fracture type, surgical methods, comorbidities, the incidence of perioperative respiratory and other complications, and hospital outcomes were collected and compared between the two groups. Subgroup analyses were also performed stratified by fracture types.
\end{abstract}

Results: A total of 1016 patients (292 females and 724 males) with a mean age of $79.4 \pm 7.3$ years were analyzed in the study, including 533 in the control group and 483 in the observation group. The overall incidence of perioperative respiratory complication, and the incidence of pulmonary infection, respiratory failure and arrhythmia in the observation group were significantly lower than the control group, especially in winter and spring. There was no difference in other complications, hospital length of stay, and total hospital costs. Further subgroup analyses showed that the incidence of heart failure and arrhythmia in the observation group was lower than that in the control group for patients with femoral neck fractures, which was different from patients with intertrochanteric fractures.

Conclusion: The incidence of perioperative respiratory complications, including pulmonary infection and respiratory failure, could be reduced in older adults with hip fractures by strengthening personal protection, including wearing medical masks, especially in winter and spring. Wearing medical masks could also effectively reduce the incidence of perioperative heart failure and arrhythmia in femoral neck fracture patients and do not increase the incidence of other complications and the burden of hospitalization.

Keywords: masks, aged, hip fractures, perioperative period, respiratory system

\section{Introduction}

Third Hospital of Hebei Medical

University, Department of Orthopaedic

Surgery, Shijiazhuang, Hebei, 05005I,

People's Republic of China

Email dryzzhang@|26.com

Zhiqian Wang

Third Hospital of Hebei Medical

University, Department of Geriatric

Orthopedics, Shijiazhuang, Hebei, 05005I.

People's Republic of China

Emailw18533|I2890@I63.com
As a common disease, hip fracture seriously affects both the physical and mental health of the elderly. Nowadays, surgery is the preferred treatment for older adults with hip fractures. ${ }^{1-4}$ However, the older adults are prone to severe traumatic stress response after the initial fracture, with increased bed rest and limited activity simultaneously. ${ }^{5}$ During this period, respiratory muscle weakness and changes in depth of breathing impair the cough capacity of elderly patients. ${ }^{6}$ Both immune and pulmonary functions decline with advancing age. ${ }^{7,8}$ These eventually lead to 
retention of airway secretion, and the occurrence of respiratory complications, such as pulmonary infection and respiratory failure, affecting both patients' surgical planning and prognosis. ${ }^{6}$ In addition, inappropriate perioperative management will not only affect the fracture recovery but easily induce multisystem complications, resulting in various organ failures, as well as increasing the risk of death. ${ }^{9-11}$

Masks, which are the important personal protective equipment, prevent the spread of respiratory infections. $^{12,13}$ In recent years, multiple studies have demonstrated this. ${ }^{14,15}$ MacIntyre et al reported that compared with the no-mask group, the incidence of clinical respiratory illness was significantly lower in the mask group. ${ }^{16} \mathrm{~A}$ systematic review suggested evidence on mask effectiveness for respiratory infection prevention was stronger in health care than in community settings. ${ }^{17}$

Therefore, the management of the respiratory system and personal protection are of great interest in preventing perioperative respiratory and other multisystem complications. Our hospital has a specialist ward for geriatric orthopedics, providing 24/7/365 geriatric support. Since 2019, we have conducted an integrated management bundle, which includes respiratory management. Since 2020, we have introduced a strict screening system for the hospitalized patients. After admission, we remind both inpatients and accompanying persons to strengthen personal protection by wearing medical masks, for the reason that medical masks can effectively filter bacteria in the air and block droplets, pollen, or dust. ${ }^{18}$

We aimed to investigate the effect of wearing medical masks on the prevention of perioperative respiratory as well as other multisystem complications in older adults with hip fractures. We hypothesized that wearing medical masks could reduce the incidence of perioperative respiratory complications without increasing the incidence of other complications and the burden of hospitalization.

\section{Patients and Methods}

\section{Patients and Groups}

The study population consisted of all patients aged 65 years or older presenting with hip fractures at a single Level I trauma center in China between Jan. 2019 and Jan. 2021. This study was overseen and approved by the institutional review board of our hospital in compliance with Helsinki's declaration, and an exemption from the informed consent was obtained. We included patients with age 65 years or older, with a definite diagnosis of hip fracture, without respiratory complications at the time of admission, and those who received surgical treatment. Patients with multiple fractures or injuries, and with pathological or open fractures, were excluded. Patients were retrospectively assigned to two groups: those admitted from Jan. 2019 to Jan. 2020 were placed in the control group; those admitted from Jan. 2020 to Jan. 2021 were placed in the observation group.

In subgroup analyses, patients were initially stratified by fracture type, including femoral neck fracture and intertrochanteric fracture. Based on the different perioperative management modalities applied, the patients of different fracture types were further assigned to observation group and control group.

\section{Perioperative Management}

Our hospital has a specialist ward for geriatric orthopedics, providing 24/7 geriatric support, including national holidays. The ward patients are assessed daily by at least two orthopedists who lead a multidisciplinary team, including an internal medicine consultant who is available to review perioperative care for patients with comorbidities, in cooperation with an anesthetic consultant.

The control group and the observation group were both treated with an integrated management bundle, including monitoring, evaluation and education, respiratory management, volume management, nutritional support, blood and thrombosis management, sedation, analgesia and education, and tube management. ${ }^{19,20}$ After admission, patients were first subjected to a comprehensive geriatric assessment to detect the potential risks, and appropriate health education for patients and their family members was adopted.

Respiratory management was listed as the following: High-risk factors of developing respiratory complications included age ( $\geq 65$ years), smoking history (smoking index $\geq 400$ ), bronchial hyperreactivity, airway bacterial colonization and others. Guidelines recommend that patients with high-risk factors should receive nebulized treatment to prevent bronchospasm reducing airway inflammation. ${ }^{21}$ In this study, patients had more than one high-risk factor. They were treated with nebulization of salbutamol sulfate, ipratropium bromide, and budesonide twice a day, and encouraged to perform respiratory function exercise regularly, such as coughing every hour. The caregivers were also informed to turn over the backs of the patients every two hours. The purpose of perioperative rehydration was to ensure the body fluid balance as much as possible. Patients were 
assessed for nutrition status with the NRS2002 nutrition screening score, and nutritional support was provided accordingly. In addition, patients were encouraged to eat preferentially by mouth, and if nutrient intake was insufficient, a gastric tube used for nasogastric feeding might help to avoid electrolyte imbalance. Routine blood test deserved close attention for ensuring the hemoglobin that should not be less than $10 \mathrm{~g} / \mathrm{dL}$. We suggested both pharmacologic thromboprophylaxis and mechanical thromboprophylaxis. For perioperative agitation and delirium, attempts should be made to identify and relieve the likely causative triggers, beyond just those drug treatments.

In addition to the above, patients in the observation group were asked to take enhanced personal protective measures, such as paying attention to hand hygiene and wearing medical masks. After admission, the patient was questioned and examined in detail, and ancillary tests were done to exclude novel coronavirus pneumonia. The precautions regarding wearing medical masks included distinguishing and avoiding touching the inside of the mask, pressing the nasal clips with both hands along the nasal bridge to ensure the mask fitted the face perfectly, and washing hands after removing the mask. Medical masks were suggested regular changing and replaced immediately if they were contaminated by body fluids or blood.

\section{Data Collection}

Demographics and clinical data of the patients including gender, age, fracture type, surgical methods, and comorbidities were collected. Outcomes including complications, seasonal distribution of perioperative respiratory complications, hospital length of stay, and total hospital costs were also collected. Based on age in the ten-year intervals, patients were divided into three groups: 65-74 years, $75-84$ years, and age $\geq 85$ years.

\section{Statistical Analysis}

We performed a power analysis for the statistics. A twosided 5\% significance level and $80 \%$ power were considered as reliable and significant. The sample size and power analysis have been computed using NCSS-PASS V11.0.7 software (https://www.ncss.com/software/pass/). The distributions of all variables were evaluated for normality by using the Kolmogorov-Smirnov test. Data satisfying normality were presented as mean \pm standard deviation. Count data were expressed in percentages (\%). $t$-test for independent samples was used when comparing normally distributed continuous variables. Pearson's chi-square test or Fisher's exact test was used for dichotomous data. All data analyses were performed using IBM SPSS Statistics for Windows, version 26.0 (IBM, Armonk, NY, USA). The level of significance was set at $P<0.05$.

\section{Results \\ Baseline Characteristics of Study Participants}

A total of 1016 patients with a mean age of $79.4 \pm 7.3$ years were analyzed in the study. The control group included 157 males and 376 females with a mean age of $79.3 \pm 7.4$ years. The observation group included 135 males and 348 females with a mean age of $79.5 \pm 7.1$ years. There was no significant difference in terms of gender, age, fracture type, surgical methods, and comorbidities between the two groups (Table $1, P>0.05$ ).

\section{Comparison of Perioperative Complications and Hospital Outcomes}

Table 2 shows that the overall incidence of respiratory complications, the incidence of pulmonary infection and respiratory failure were significantly lower in the observation group than that in the control group (all $P<0.05$ ). In terms of seasonal distribution, the incidence of respiratory complications in winter and spring accounted for $29.3 \%$ and $29.1 \%$, respectively, in the observation group, which was lower than the control group (44.1\% and $42.3 \%$, respectively, $P<0.05$ ). Seasonal distribution for the incidence of respiratory complications in summer and autumn, hospital outcomes including LOS and THC, and incidence of other complications except for arrhythmia were not significantly different between the two groups (Table 2 and Figure 1).

\section{Subgroup Analysis Stratified by Fracture Type}

There was no significant difference presented between and control groups in terms of characteristics at baseline in either patients with femoral neck fractures or those with intertrochanteric fractures (all $P>0.05$, Table 3). When only patients with femoral neck fractures were analyzed, the incidence of complications in the observation group, including respiratory system, pulmonary infection, respiratory failure, heart failure and arrhythmia, were significantly lower than the control group (all $P<0.05$ ). However, only the overall incidence of respiratory complications and the incidence of pulmonary infection were statistically different 
Table I Comparisons of Patient Demographics and Comorbidities Between Two Groups

\begin{tabular}{|c|c|c|c|c|c|}
\hline & Total & Observation & Control & $\chi^{2} / t$ & $\mathbf{P}$ \\
\hline Age, mean \pm SD (years) & $79.4 \pm 7.3$ & $79.5 \pm 7.1$ & $79.3 \pm 7.4$ & -0.341 & 0.733 \\
\hline Females, n (\%) & $724(71.3)$ & $348(72.0)$ & $376(70.5)$ & 0.280 & 0.596 \\
\hline \multicolumn{6}{|l|}{ Distribution of age group, $\mathrm{n}(\%)$} \\
\hline $65-74$ years & $292(28.7)$ & $138(28.6)$ & 154 (28.9) & 0.277 & 0.871 \\
\hline $75-84$ years & $454(44.7)$ & $213(44.1)$ & $24 I(45.2)$ & & \\
\hline$\geq 85$ years & $270(26.6)$ & $132(27.3)$ & $138(25.9)$ & & \\
\hline \multicolumn{6}{|l|}{ Fracture types, n (\%) } \\
\hline Femoral neck fractures & $478(47.0)$ & $226(46.8)$ & $252(47.3)$ & 0.024 & 0.876 \\
\hline Intertrochanteric fractures & $538(53.0)$ & $257(53.2)$ & $28 \mid(52.7)$ & & \\
\hline \multicolumn{6}{|l|}{ Surgical methods, n (\%) } \\
\hline Artificial joint replacement & 439 (43.2) & $210(43.5)$ & $229(43.0)$ & 0.027 & 0.869 \\
\hline Closed reduction and internal fixation & $577(56.8)$ & $273(56.5)$ & $304(57.0)$ & & \\
\hline \multicolumn{6}{|l|}{ Comorbidities, n (\%) } \\
\hline Hypertension & $409(40.3)$ & $191(4 \mid .9)$ & $218(47.2)$ & 0.688 & 0.407 \\
\hline Coronary heart disease & $284(28.0)$ & $129(26.7)$ & $155(29.1)$ & 0.708 & 0.400 \\
\hline Cerebrovascular disease & $429(42.2)$ & $214(44.3)$ & $215(40.3)$ & 1.636 & 0.201 \\
\hline Diabetes & $217(21.4)$ & $100(20.7)$ & $117(22.0)$ & 0.235 & 0.628 \\
\hline
\end{tabular}

Notes: Values are presented as the number (\%). Plus-minus values of age is means \pm SD.

Table 2 Comparisons of Patient Perioperative Complications and Hospital Outcomes Between Two Groups

\begin{tabular}{|c|c|c|c|c|c|}
\hline Complications & Total & Observation & Control & $\chi^{2}$ & $P$ \\
\hline \multicolumn{6}{|l|}{ Respiratory complications, n (\%) } \\
\hline Overall incidence & $344(33.9)$ & $142(29.4)$ & $202(4 \mid .8)$ & 8.173 & $0.004 *$ \\
\hline Pulmonary infection & $307(30.2)$ & $125(25.9)$ & $182(37.7)$ & 0.211 & $0.004 *$ \\
\hline Respiratory failure & $122(12.0)$ & $46(9.5)$ & $76(14.3)$ & 5.377 & $0.020 *$ \\
\hline \multicolumn{6}{|l|}{ Other complications, $\mathrm{n}(\%)$} \\
\hline Heart failure & $378(37.2)$ & $178(36.9)$ & $200(37.5)$ & 3.237 & 0.846 \\
\hline Arhythmia & $280(27.6)$ & $118(24.4)$ & $162(30.4)$ & 4.513 & $0.034^{*}$ \\
\hline Deep venous thrombosis of the lower limbs & $485(47.8)$ & $242(50.1)$ & $243(45.6)$ & 2.068 & 0.150 \\
\hline Anemia & 723 (7I.2) & $356(73.7)$ & $367(68.9)$ & 2.905 & 0.088 \\
\hline Low protein & $605(59.5)$ & $284(58.8)$ & $321(60.2)$ & 0.214 & 0.644 \\
\hline Electrolyte disturbances & $586(57.7)$ & $270(55.9)$ & $316(59.3)$ & 1.190 & 0.275 \\
\hline \multicolumn{6}{|l|}{ Hospital outcomes, n (\%) } \\
\hline Length of hospital stay & $13.0 \pm 5.0$ & $13.2 \pm 4.9$ & $12.8 \pm 5.2$ & -1.250 & 0.212 \\
\hline Total hospital costs & $6.7 \pm 1.9$ & $6.7 \pm 1.7$ & $6.7 \pm 2.1$ & 0.084 & 0.933 \\
\hline
\end{tabular}

Notes: Plus-minus values are means $\pm S D$. In number of respiratory complications and other complications, values are presented as the number $(\%)$. $* P<0.05$, statistical significance.

between the two groups for intertrochanteric fracture patients (all $P<0.05$ ). These differences are summarized in Table 4 .

\section{Discussion}

In this retrospective cohort study, we analyzed the effect of wearing medical masks on perioperative respiratory complications and other complications in older adults with hip fractures. Our results show that the overall incidence of perioperative respiratory complication, and the incidence of pulmonary infection, respiratory failure and arrhythmia in the observation group were significantly lower than the control group, especially in winter and spring. There was no difference in other complications, hospital length of stay, and total hospital costs. Further subgroup analyses 


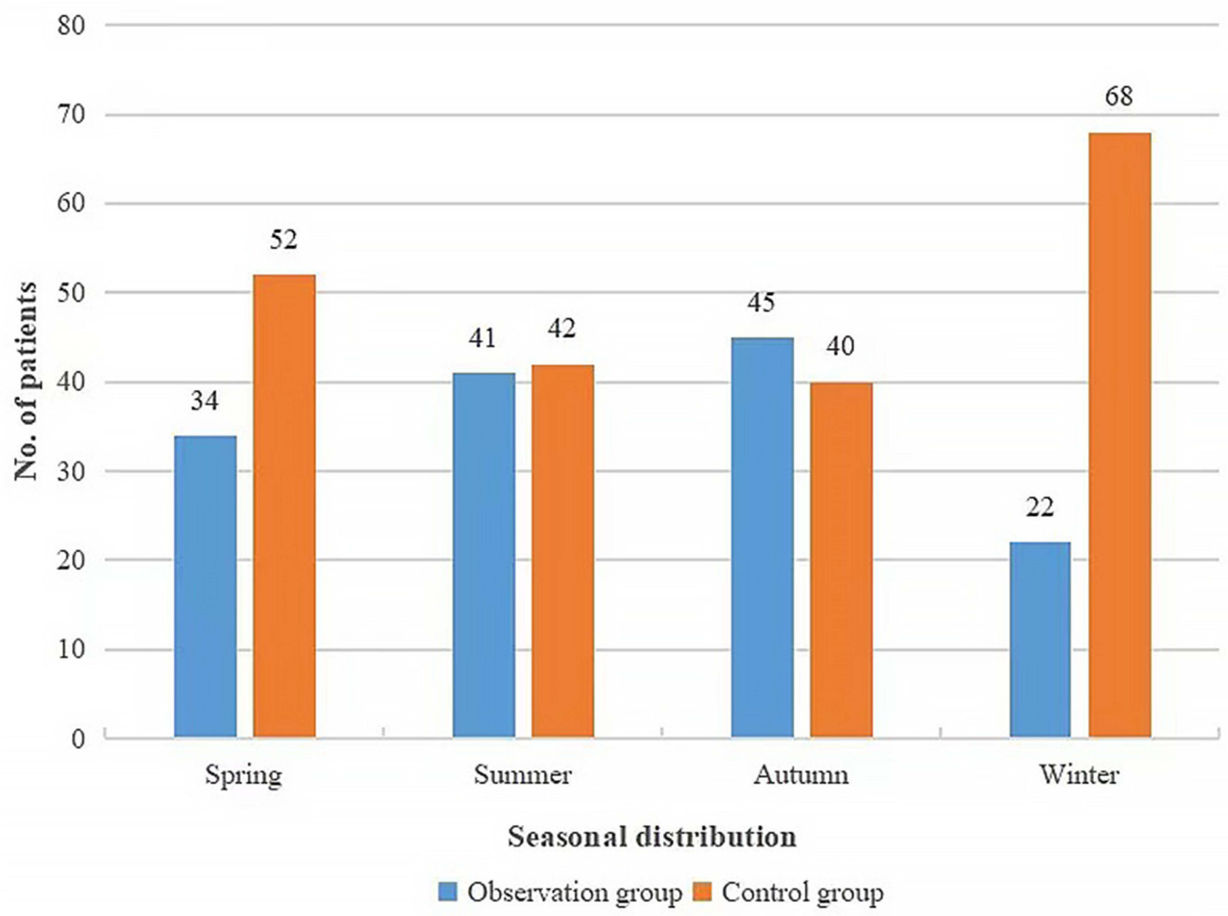

Figure I Seasonal distribution of respiratory complications between control and observation groups.

showed the incidence of heart failure and arrhythmia in the observation group was lower than in the control group for patients with femoral neck fractures, which was different from patients with intertrochanteric fractures.
Pulmonary infection is one of the most common perioperative complications in older adults with hip fractures. According to the lung initiation doctrine in multi-organ failure, perioperative pulmonary infection is more prone to

Table 3 Patient Demographics and Comorbidities Stratified by Fracture Types

\begin{tabular}{|c|c|c|c|c|c|c|}
\hline & \multicolumn{3}{|c|}{ Femoral Neck Fractures } & \multicolumn{3}{|c|}{ Intertrochanteric Fractures } \\
\hline & Observation & Control & $P$ & Observation & Control & $\boldsymbol{P}$ \\
\hline Age, mean $\pm \mathrm{SD}$ (years) & $78.0 \pm 7.1$ & $78.3 \pm 7.3$ & 0.703 & $80.7 \pm 6.9$ & $80.2 \pm 7.3$ & 0.419 \\
\hline Females, n (\%) & $160(70.8)$ & $173(68.7)$ & 0.610 & $188(73.2)$ & $203(72.2)$ & 0.813 \\
\hline $\begin{array}{l}\text { Distribution of age group, } n(\%) \\
65-74 \text { years } \\
75-84 \text { years } \\
\geq 85 \text { years }\end{array}$ & $\begin{array}{l}85(37.6) \\
95(42.0) \\
46(20.4)\end{array}$ & $\begin{array}{c}85(33.7) \\
107(42.5) \\
60(23.8)\end{array}$ & 0.562 & $\begin{array}{l}53(20.6) \\
118(45.9) \\
86(33.5)\end{array}$ & $\begin{array}{c}69(24.6) \\
134(47.7) \\
78(27.7)\end{array}$ & 0.295 \\
\hline $\begin{array}{l}\text { Surgical methods, } \mathrm{n}(\%) \\
\text { Artificial hip joint replacement } \\
\text { Closed reduction and internal } \\
\text { fixation }\end{array}$ & $\begin{array}{c}222(88.1) \\
30(11.9)\end{array}$ & $\begin{array}{c}207(91.6) \\
19(8.4)\end{array}$ & 0.208 & $\begin{array}{c}3(1.2) \\
254(98.8)\end{array}$ & $\begin{array}{c}7(2.5) \\
274(97.5)\end{array}$ & 0.414 \\
\hline $\begin{array}{l}\text { Comorbidities, } \mathrm{n}(\%) \\
\text { Hypertension } \\
\text { Coronary heart disease } \\
\text { Cerebrovascular disease } \\
\text { Diabetes }\end{array}$ & $\begin{array}{l}97(42.9) \\
63(27.9) \\
92(40.7) \\
39(17.3)\end{array}$ & $\begin{array}{l}110(43.7) \\
68(27.0) \\
94(37.3) \\
49(19.4)\end{array}$ & $\begin{array}{l}0.872 \\
0.827 \\
0.446 \\
0.538\end{array}$ & $\begin{array}{l}108(42.0) \\
66(25.7) \\
122(47.5) \\
61(23.7)\end{array}$ & $\begin{array}{l}130(46.3) \\
87(31.0) \\
121(43.1) \\
68(24.2)\end{array}$ & $\begin{array}{l}0.323 \\
0.175 \\
0.305 \\
0.900\end{array}$ \\
\hline
\end{tabular}

Notes: Plus-minus values are means \pm SD. In number of females, distribution of age group, surgical methods, and comorbidities, values are presented as the number (\%). 
Table 4 Patient Perioperative Complications and Hospital Outcomes Stratified by Fracture Types

\begin{tabular}{|c|c|c|c|c|c|c|}
\hline & \multicolumn{3}{|c|}{ Femoral Neck Fractures } & \multicolumn{3}{|c|}{ Intertrochanteric Fractures } \\
\hline & Observation & Control & $P$ & Observation & Control & $\mathbf{P}$ \\
\hline \multicolumn{7}{|l|}{ Respiratory complications, n (\%) } \\
\hline Overall incidence & $65(28.8)$ & $95(37.7)$ & $0.039 *$ & $77(30.0)$ & $107(38.1)$ & $0.047^{*}$ \\
\hline Pulmonary infection & $57(25.2)$ & $85(33.7)$ & $0.042 *$ & $68(26.5)$ & $97(34.5)$ & $0.043^{*}$ \\
\hline Respiratory failure & $16(7.1)$ & $33(13.1)$ & $0.030 *$ & $30(11.7)$ & $43(15.3)$ & 0.219 \\
\hline \multicolumn{7}{|l|}{ Other complications, n (\%) } \\
\hline Heart failure & $67(29.6)$ & $97(38.5)$ & $0.042 *$ & III (43.0) & $103(36.7)$ & 0.131 \\
\hline Arhythmia & $55(24.3)$ & $83(32.9)$ & $0.038^{*}$ & $63(24.5)$ & $79(28.1)$ & 0.344 \\
\hline $\begin{array}{l}\text { Deep venous thrombosis of the } \\
\text { lower limbs }\end{array}$ & $102(45.1)$ & $105(41.7)$ & 0.445 & $140(54.4)$ & $138(49.1)$ & 0.214 \\
\hline Anemia & $151(66.8)$ & $158(62.7)$ & 0.347 & $205(79.8)$ & $209(74.4)$ & 0.138 \\
\hline Low protein & $127(56.2)$ & $149(59.1)$ & 0.517 & $157(61.1)$ & $172(6 \mid .2)$ & 0.977 \\
\hline Electrolyte disturbances & $135(59.7)$ & $150(59.5)$ & 0.963 & $135(52.5)$ & $166(59.1)$ & 0.127 \\
\hline \multicolumn{7}{|l|}{ Hospital outcomes, n (\%) } \\
\hline Length of hospital stay & $\mid 4.1 \pm 5.3$ & $|3.3 \pm 5|$. & 0.075 & $12.4 \pm 4.3$ & $12.4 \pm 5.2$ & 0.999 \\
\hline Total hospital costs & $7.2 \pm 1.8$ & $7.1 \pm 2.0$ & 0.751 & $6.3 \pm 1.6$ & $6.4 \pm 2.0$ & 0.693 \\
\hline
\end{tabular}

Notes: Plus-minus values are means $\pm S D$. In number of respiratory complications and other complications, values are presented as the number $(\%)$. $* P<0.05$, statistical significance.

cause respiratory failure, eventually leading to the failure of a variety of other organs. It can be explained in several aspects. First, pulmonary functions are changed with advancing age, including decreased lung compliance, atrophic of respiratory mucosa, diminished ciliary movement and decrements in lung volumes and respiratory rates. The changes make the respiratory tract less defensive and less resilient to the external environment, eventually creating conditions for the invasion of pathogenic microorganisms. ${ }^{22-25}$ Second, large amounts of catecholamines are released under the influence of traumatic stress, ${ }^{26-30}$ causing the patient in a state of hypermetabolism with oxygen consumption increased. Third, the induced immune-inflammatory response may lead to mitochondrial functional impairment. ${ }^{31,32}$ As a result, there appear oxygen utilization disorders, which can further cause intracellular hypoxia. Together with the immune dysfunction, it is more likely to cause lung infection and respiratory failure in the patients.

Our results indicated that the underlying post-trauma acute lung inflammation and injury seemed to be attenuated by respiratory management, which avoided poor sputum drainage and improves lung ventilatory function. It has been widely known that ciliary motility at the bronchial mucosal surface can clear pathogenic bacteria, and the alveolar macrophages can phagocytose and kill pathogenic bacteria to maintain lung immune homeostasis. ${ }^{33,34}$
The seasonal variations in winter and spring easily lead to the dysfunctional respiratory system and reduced respiratory defense, and the various kinds of bacteria or viruses are more likely to invade the human respiratory system, eventually inducing lung infection, respiratory failure, and other diseases. ${ }^{35-37}$ Strengthening personal protection by wearing a mask is an important means to slow down the spread of bacteria and viruses, and to reduce the chance of cross-infection in populations. ${ }^{38,39}$ This may explain the results we obtained of seasonal differences.

The incidence of perioperative arrhythmia was significantly lower in the observation group. This result might be associated with a reduced incidence of pulmonary infection. Once pulmonary infection occurs, myocardial oxygen demand increases due to infection and fever, and oxygenation of the blood decreases caused by ventilation-perfusion mismatch, inducing myocardial suppression, eventually leading to arrhythmia. ${ }^{40}$ Fluoroquinolones and macrolides may increase the risk of ventricular arrhythmias. ${ }^{41}$ In addition, pulmonary hypoxia may excite the sympathoadrenomedullary system to release hormones, which could act directly on cardiomyocytes and then cause arrhythmia. $^{42}$

In addition, total hospital costs and length of stay were not increased in the observation group, even with a strict screening system. We speculate that it may be related to the following reasons. The pulmonary infections are 
effectively prevented by strengthened personal protection. The surgical delay, extension of the postoperative recovery cycle and the cost of treatment such as antibiotics are further avoided. Moreover, it also avoids the aggravation of the patient's condition and the occurrence of other complications, reducing the risk of ICU transfer.

Our subgroup analyses demonstrated that for patients with femoral neck fractures, the incidence of heart failure and arrhythmia in the observation group was lower than that in the control group, which was not found in patients with intertrochanteric fractures. The possible cause of the difference is that intertrochanteric fractures tend to receive greater violence and be more serious than femoral neck fractures, which are manifested in abundant local blood supply, obvious swelling, ecchymosis, and severe pain. ${ }^{43-45}$

\section{Limitations}

There were several limitations of this study. First, it was a single-center, retrospective cohort study and the intrinsic limitation of design seemed to be inescapable. Second, the limited statistical power concerning complications in this study implied that the results should be interpreted with caution. In addition, the information about calcium and vitamin $\mathrm{D}$ and the use of medications that can affect vitamin D metabolism were not recorded.

\section{Conclusions}

The incidence of respiratory complications including perioperative pulmonary infection and respiratory failure can be reduced in older adults with hip fractures by strengthening personal protection by wearing medical masks, especially in winter and spring. Wearing medical masks can also effectively reduce the incidence of perioperative heart failure and arrhythmia in femoral neck fracture patients and do not increase other complications rates and the burden of hospitalization.

\section{Data Sharing Statement}

The data used to support the findings of this study are available from Zhiqian Wang upon request.

\section{Ethical Approval and Informed Consent}

This study was approved by the institutional review board of the third Hospital of Hebei Medical University (W2021-0701) in compliance with the Helsinki, and the declaration and consent were waived for its retrospective nature. All data were anonymized before the analysis to safeguard patient privacy.

\section{Funding}

The study was financially supported by the 2019 Hebei Provincial Department of Finance Geriatric Disease Prevention and Control Funds.

\section{Disclosure}

The authors declare that there is no conflict of interest regarding the publication of this paper.

\section{References}

1. Choi HJ, Kim E, Shin YJ, Choi BY, Kim YH, Lim TH. The timing of surgery and mortality in elderly hip fractures: a retrospective, multicenteric cohort study. Indian J Orthop. 2014;48(6):599-604. doi:10.4103/0019-5413.144232

2. Lee DJ, Elfar JC. Timing of hip fracture surgery in the elderly. Geriatr Orthop Surg Rehabil. 2014;5(3):138-140. doi:10.1177/ 2151458514537273

3. Moja L, Piatti A, Pecoraro V, et al. Timing matters in hip fracture surgery: patients operated within 48 hours have better outcomes. A meta-analysis and meta-regression of over 190,000 patients. PLoS One. 2012;7(10):e46175. doi:10.1371/journal.pone.0046175

4. Simunovic N, Devereaux PJ, Sprague S, et al. Effect of early surgery after hip fracture on mortality and complications: systematic review and meta-analysis. CMAJ. 2010;182(15):1609-1616. doi:10.1503/ cmaj.092220

5. Wang $\mathrm{Z}$, Ehnert $\mathrm{S}$, Ihle $\mathrm{C}$, et al. Increased oxidative stress response in granulocytes from older patients with a hip fracture may account for slow regeneration. Oxid Med Cell Longev. 2014;2014:1-9.

6. Guo J, Gao C, Xin H, et al. The application of "upper-body yoga" in elderly patients with acute hip fracture: a prospective, randomized, and single-blind study. $J$ Orthop Surg Res. 2019;14(1):250. doi:10.1186/s13018-019-1295-6

7. Fowler RW. Ageing and lung function. Age Ageing. 1985;14 (4):209-215. doi:10.1093/ageing/14.4.209

8. Lord JM. The effect of ageing of the immune system on vaccination responses. Hum Vaccin Immunother. 2013;9(6):1364-1367. doi: $10.4161 / \mathrm{hv} .24696$

9. Zhao K, Zhang J, Li J, et al. In-hospital postoperative pneumonia following geriatric intertrochanteric fracture surgery: incidence and risk factors. Clin Interv Aging. 2020;15:1599-1609. doi:10.2147/CIA.S268118

10. Bohl DD, Sershon RA, Saltzman BM, Darrith B, Della Valle CJ. Incidence, risk factors, and clinical implications of pneumonia after surgery for geriatric hip fracture. J Arthroplasty. 2018;33(5):15521556 e1551. doi:10.1016/j.arth.2017.11.068

11. Chatterton BD, Moores TS, Ahmad S, Cattell A, Roberts PJ. Cause of death and factors associated with early in-hospital mortality after hip fracture. Bone Joint J. 2015;97-B(2):246-251. doi:10.1302/0301620X.97B2.35248

12. MacIntyre CR, Chughtai AA. Facemasks for the prevention of infection in healthcare and community settings. BMJ. 2015;350:h694. doi:10.1136/bmj.h694

13. Dhama K, Khan S, Tiwari R, et al. Coronavirus Disease 2019-COVID-19. Clin Microbiol Rev. 2020;33(4):e00028-20. doi:10.1128/CMR.00028-20.

14. Liang M, Gao L, Cheng C, et al. Efficacy of face mask in preventing respiratory virus transmission: a systematic review and meta-analysis. Travel Med Infect Dis. 2020;36:101751. doi:10.1016/j. tmaid.2020.101751

15. Howard J, Huang A, Li Z, et al. An evidence review of face masks against COVID-19. Proc Natl Acad Sci USA. 2021;118(4): e2014564118. doi:10.1073/pnas.2014564118 
16. MacIntyre CR, Zhang Y, Chughtai AA, et al. Cluster randomised controlled trial to examine medical mask use as source control for people with respiratory illness. BMJ Open. 2016;6(12):e012330. doi:10.1136/bmjopen-2016-012330

17. Chou R, Dana T, Jungbauer R, Weeks C, McDonagh MS. Masks for prevention of respiratory virus infections, including SARS-CoV-2, in health care and community settings: a living rapid review. Ann Intern Med. 2020;173(7):542-555. doi:10.7326/M20-3213

18. Sterr CM, Nickel IL, Stranzinger C, Nonnenmacher-Winter CI, Gunther F. Medical face masks offer self-protection against aerosols: an evaluation using a practical in vitro approach on a dummy head. PLoS One. 2021;16(3):e0248099. doi:10.1371/journal.pone.0248099

19. Zanker J, Duque G. Rapid geriatric assessment of hip fracture. Clin Geriatr Med. 2017;33(3):369-382. doi:10.1016/j.cger.2017.03.003

20. Avenell A, Smith TO, Curtain JP, Mak JC, Myint PK. Nutritional supplementation for hip fracture aftercare in older people. Cochrane Database Syst Rev. 2016;11:CD001880. doi:10.1002/14651858. CD001880.pub6

21. The expert group of Chinese expert consensus statement on multidisciplinary perioperative airway management (2016 version). Chinese consensus statement on multi-disciplinary perioperative airway management (2016 version). Chin J Clin Thorac Cardiovasc Surg. 2016;23(7):641-645.

22. Chen W, Lian J, Ye JJ, et al. Ethyl pyruvate reverses development of Pseudomonas aeruginosa pneumonia during sepsis-induced immunosuppression. Int Immunopharmacol. 2017;52:61-69. doi:10.1016/j.intimp.2017.08.024

23. Fliegauf M, Benzing T, Omran H. When cilia go bad: cilia defects and ciliopathies. Nat Rev Mol Cell Biol. 2007;8(11):880-893. doi: $10.1038 / \mathrm{nrm} 2278$

24. Khadzhieva MB, Kuzovlev AN, Salnikova LE. Pneumonia: host susceptibility and shared genetics with pulmonary function and other traits. Clin Exp Immunol. 2019;198(3):367-380. doi:10.1111/ cei. 13367

25. Mannino DM, Davis KJ, Kiri VA. Chronic obstructive pulmonary disease and hospitalizations for pneumonia in a US cohort. Respir Med. 2009;103(2):224-229. doi:10.1016/j.rmed.2008.09.005

26. von Friesendorff M, McGuigan FE, Wizert A, et al. Hip fracture, mortality risk, and cause of death over two decades. Osteoporos Int. 2016;27(10):2945-2953. doi:10.1007/s00198-016-3616-5

27. Lin JC, Liang WM. Mortality, readmission, and reoperation after hip fracture in nonagenarians. BMC Musculoskelet Disord. 2017;18 (1):144. doi:10.1186/s12891-017-1493-5

28. Gan L, Chen X, Sun T, et al. Significance of serum mtDNA concentration in lung injury induced by hip fracture. Shock. 2015;44 (1):52-57. doi:10.1097/SHK.0000000000000366

29. Zhang JZ, Wang J, Qu WC, et al. Plasma mitochondrial DNA levels were independently associated with lung injury in elderly hip fracture patients. Injury. 2017;48(2):454 459. doi:10.1016/j.injury.2017.01.009

30. Keel M, Trentz O. Pathophysiology of polytrauma. Injury. 2005;36 (6):691-709. doi:10.1016/j.injury.2004.12.037

31. Valdivieso AG, Santa-Coloma TA. CFTR activity and mitochondrial function. Redox Biol. 2013;1:190-202. doi:10.1016/j.redox.2012.11.007
32. Huttemann M, Helling S, Sanderson TH, et al. Regulation of mitochondrial respiration and apoptosis through cell signaling: cytochrome c oxidase and cytochrome $\mathrm{c}$ in ischemia/reperfusion injury and inflammation. Biochim Biophys Acta. 2012;1817(4):598-609. doi:10.1016/j.bbabio.2011.07.001

33. Westphalen K, Gusarova GA, Islam MN, et al. Sessile alveolar macrophages communicate with alveolar epithelium to modulate immunity. Nature. 2014;506(7489):503-506. doi:10.1038/nature12902

34. Robb CT, Regan KH, Dorward DA, Rossi AG. Key mechanisms governing resolution of lung inflammation. Semin Immunopathol. 2016;38(4):425-448. doi:10.1007/s00281-016-0560-6

35. Xu PB, Lou JS, Ren Y, Miao CH, Deng XM. Gene expression profiling reveals the defining features of monocytes from septic patients with compensatory anti-inflammatory response syndrome. J Infect. 2012;65(5):380-391. doi:10.1016/j.jinf.2012.08.001

36. Visser T, Pillay J, Koenderman L, Leenen LP. Postinjury immune monitoring: can multiple organ failure be predicted? Curr Opin Crit Care. 2008;14(6):666-672. doi:10.1097/MCC.0b013e3283196522

37. Hoth JJ, Wells JD, Jones SE, Yoza BK, McCall CE. Complement mediates a primed inflammatory response after traumatic lung injury. J Trauma Acute Care Surg. 2014;76(3):601-608;discussion 608-609. doi:10.1097/TA.0000000000000129

38. Barasheed O, Alfelali M, Mushta S, et al. Uptake and effectiveness of facemask against respiratory infections at mass gatherings: a systematic review. Int $J$ Infect Dis. 2016;47:105-111.

39. Siegel JD, Rhinehart E, Jackson M, Chiarello L; Health Care Infection Control Practices Advisory C. 2007 guideline for isolation precautions: preventing transmission of infectious agents in health care settings. Am J Infect Control. 2007;35(10 Suppl 2):S65-S164. doi:10.1016/j.ajic.2007.10.007

40. Musher DM, Rueda AM, Kaka AS, Mapara SM. The association between pneumococcal pneumonia and acute cardiac events. Clin Infect Dis. 2007;45(2):158-165. doi:10.1086/518849

41. Cubeddu LX. QT prolongation and fatal arrhythmias: a review of clinical implications and effects of drugs. Am J Ther. 2003;10 (6):452-457. doi:10.1097/00045391-200311000-00013

42. Lazzara R, Marchi S. Electrophysiologic Mechanisms for the Generation of Arrhythmias with Adrenergic Stimulation. Berlin Heidelberg: Springer, 1989. doi:10.1007/978-3-642-74317-7_19

43. Cui H, Chen K, Lv S, Yuan C, Wang Y. An analysis of perioperative hidden blood loss in femoral intertrochanteric fractures: bone density is an important influencing factor. BMC Musculoskelet Disord. 2021;22(1):6. doi:10.1186/s12891-020-03922-x

44. Yu X, Zhang H, Zhang X, et al. Effects of the ratios of marrow cavity diameter to intramedullary nail diameter from different layers on blood loss during perioperative period for femoral intertrochanteric fractures. Medicine. 2019;98(37):e16936. doi:10.1097/MD.000000 0000016936

45. Uzun E, Günay AE, Karaman İ, Mısır A, Kızkapan TB, Özçamdallı M. Unusual combination of femoral head dislocation associated acetabular fracture with multipart femoral fractures: case report. Int J Surg Case Rep. 2017;34:32-35. doi:10.1016/j.ijscr.201 7.02 .043
Clinical Interventions in Aging

\section{Publish your work in this journal}

Clinical Interventions in Aging is an international, peer-reviewed journal focusing on evidence-based reports on the value or lack thereof of treatments intended to prevent or delay the onset of maladaptive correlates of aging in human beings. This journal is indexed on PubMed Central, MedLine, CAS, Scopus and the Elsevier
Bibliographic databases. The manuscript management system is completely online and includes a very quick and fair peer-review system, which is all easy to use. Visit http://www.dovepress.com/ testimonials.php to read real quotes from published authors. 